\title{
Amebic colitis: colonoscopic appearance
}
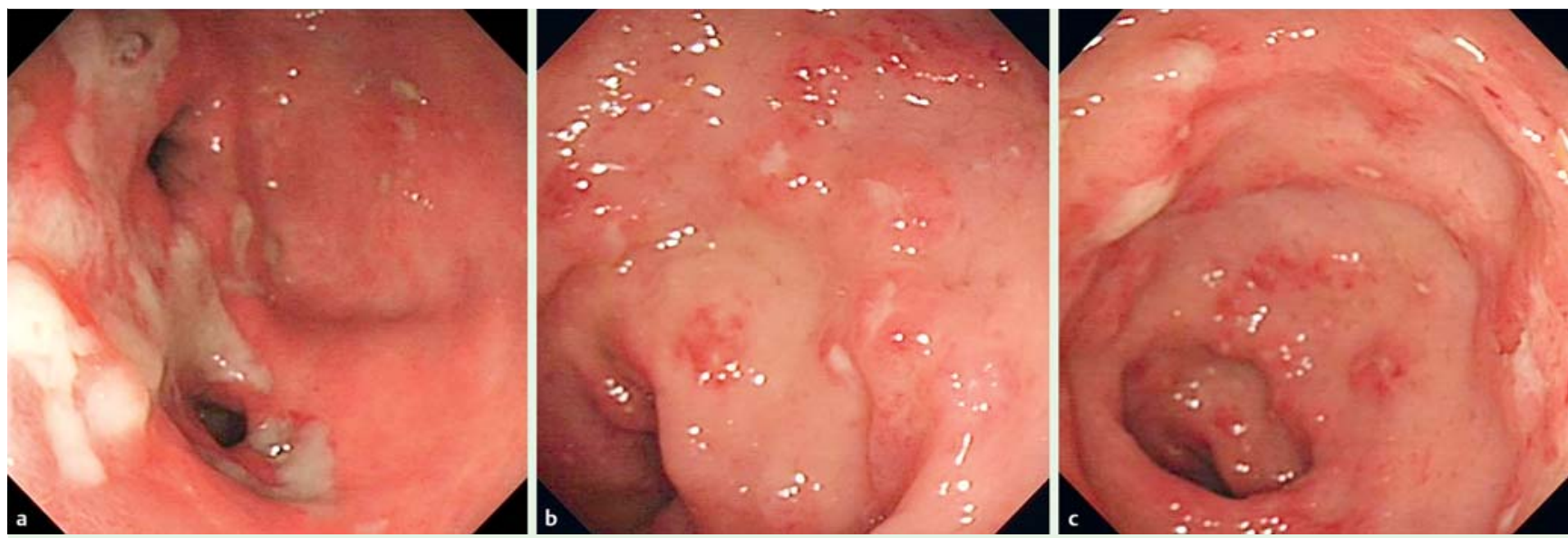

Fig. 1 Colonoscopic views showing multiple discrete ulcers with surrounding erythema in: a the cecum; $\mathbf{b}$ the sigmoid colon; $\mathbf{c}$ the rectum.

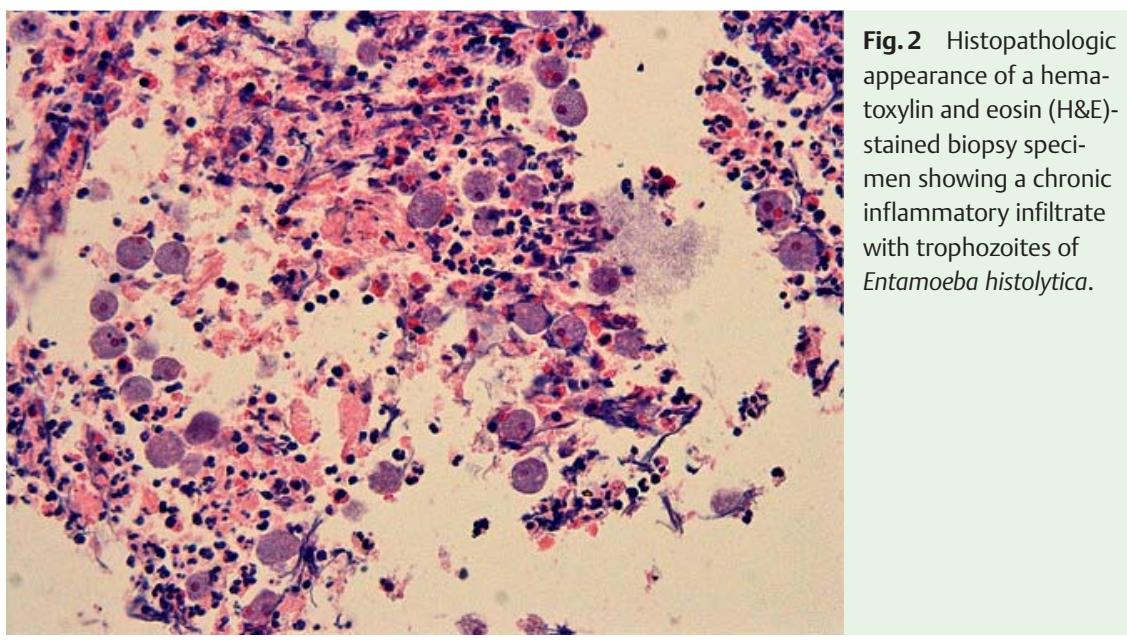

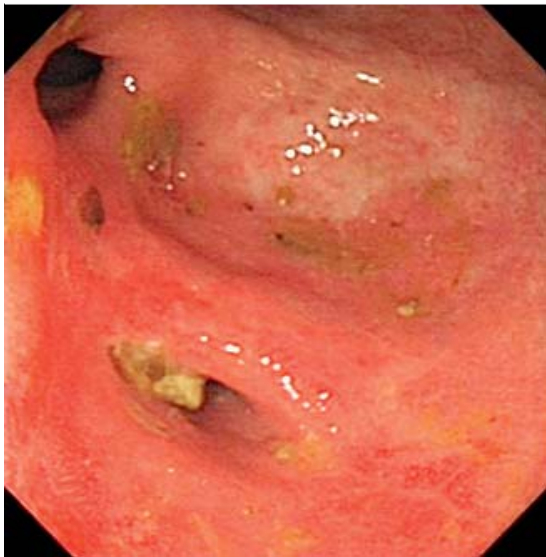

Fig. 3 View during follow-up endoscopy performed 4 weeks later showing marked improvement in the ulcers.

The most common symptoms are those of diarrhea, abdominal pain, and rectal bleeding. The diagnosis is usually made when histologic evaluation of colonic biopsies reveals trophozoites within an inflammatory infiltrate. It is challenging and important for gastroenterologists to distinguish amebic colitis from acute ulcerative colitis as the administration of corticosteroids to patients with amebic colitis can result in fulminant disease.

Endoscopy_UCTN_Code_CCL_1AD_2AZ

Competing interests: None 
Na Li ${ }^{1,2}$, Hai-hong Wang1, Xiao-jun Zhao ${ }^{1}$, Jian-qiu Sheng ${ }^{1}$

${ }^{1}$ Department of Gastroenterology, The Military General Hospital of Beijing PLA, Beijing, China

${ }^{2}$ Medical School of Chinese PLA, Beijing, China
Bibliography

Dol http://dx.doi.org/

10.1055/s-0034-1377208

Endoscopy 2015; 47: E145-E146

(C) Georg Thieme Verlag KG

Stuttgart · New York

ISSN 0013-726X
Corresponding author

Jian-qiu Sheng, MD

Department of Gastroenterology

The Military General Hospital of Beijing PLA

Nanmencang 5\#

Dongcheng District

Beijing 100700

China

jianqiu@263.net 